\title{
Correlations of Handgrip Strength with Selected Hand-Arm-Anthropometric Variables in Indian Inter-university Female Volleyball Players
}

Authors' Affiliation:

Department of Sports Medicine and Physiotherapy, Guru Nanak Dev University, Amritsar, India

* Corresponding Author;

Address: Department of Sports Medicine and Physiotherapy, Guru Nanak Dev University, Amritsar-143005, Punjab, India

E-mail: drkoley@yahoo.co.uk

Received: Mar 31, 2011

Accepted: Jul 20, 2011

Key Words: Anthropometry; Grip; Hand Strength; Volleyball; Female
Shyamal Koley*, PhD and Satinder Pal Kaur, MSPT

\begin{abstract}
Purpose: The purpose of this study was to estimate the dominant handgrip strength and its correlations with some hand and arm anthropometric variables in 101 randomly selected Indian inter-university female volleyball players aged 18-25 years (mean age $20.52 \pm 1.40$ ) from six Indian universities.
\end{abstract}

Methods: Three anthropometric variables, i.e. height, weight, BMI, two hand anthropometric variables, viz. right and left hand width and length, four arm anthropometric variables, i.e. upper arm length, lower arm length, upper extremity length, upper arm circumference and dominant right and non-dominant handgrip strength were measured among Indian inter-university female volleyball players by standard anthropometric techniques.

Results: The findings of the present study indicated that Indian female volleyball players had higher mean values in eleven variables and lesser mean values in two variables than their control counterparts, showing significant differences $(P<0.032-0.001)$ in height $(t=2.63)$, weight $(t=8.66)$, left hand width $(t=2.10)$, left and right hand length $(t=9.99$ and 10.40 respectively), right upper arm length $(t=8.48)$, right forearm length $(t=5.41)$, dominant (right) and non-dominant (left) handgrip strength $(t=9.37$ and 6.76 respectively). In female volleyball players, dominant handgrip strength had significantly positive correlations $(P \leq 0.01)$ with all the variables studied.

Conclusion: It may be concluded that dominant handgrip strength had strong positive correlations with all the variables studied in Indian interuniversity female volleyball players.

Asian Journal of Sports Medicine, Volume 2 (Number 4), December 2011, Pages: 220-226

\section{INTRODUCTION}

$\mathrm{V}$ olleyball is an intermittent sport. It requires players to participate in frequent short bouts of high-intensity exercise, followed by periods of lowintensity activity ${ }^{[1,2]}$. The high-intensity bouts of exercise, coupled with the total duration of the match requires players to have well-developed aerobic and anaerobic alactic (ATP-CP) energy systems ${ }^{[2,3]}$. As a result, volleyball players require well-developed speed, agility, upper-body and lower body muscular power, and maximal aerobic power. Several studies have examined the relationships between anthropometric and physiological characteristics of volleyball players ${ }^{[4,5]}$.

The power of handgrip is the result of forceful flexion of all finger joints with the maximum voluntary 
force that the subject is able to exert under normal biokinetic conditions ${ }^{[6,7]}$, which uses several muscles in the hand and the forearm ${ }^{[8]}$. The estimation of handgrip strength is of immense importance in sports like wrestling, tennis, football, handball, basketball, volleyball, and baseball where a sufficient degree of grip strength is necessary to be successful. For example, without adequate grip and forearm strength, tennis players may run the risk of developing lateral epicondylitis, commonly known as tennis elbow. Often overlooked or taken for granted, the strength of one's grip plays a key role in injury prevention and overall strength development ${ }^{[9-12]}$. In many cases, strengthening of the grip has been a prescription for rehabilitation from injuries such as golfers and tennis elbow. These ailments are often caused by improper strength ratios between the elbow muscles and the forearm muscles. If the elbow flexors, like the biceps and brachialis are too strong for the forearm flexors, uneven tension accumulates in the soft tissue and results in elbow pain ${ }^{[13]}$. Recent studies related to handgrip strength and selected arm-anthropometric variables in Indian basketball and volleyball players were also reported ${ }^{[14,15]}$.

Grip strength determines the handedness of an individual, an important field of population variation study. It is often used as an indicator of overall physical strength ${ }^{[16,17]}$, hand and forearm muscle performances ${ }^{[18]}$ and as a functional index of nutritional status ${ }^{[19-28]}$ and physical performance ${ }^{[29,30]}$. Handgrip strength is a physiological variable that is affected by a number of factors including age, gender and body size.

To the best of our knowledge, the information related to the correlations of hand- and armanthropometric variables and grip strength in volleyball players remains largely unreported so far. In fact, handgrip strength has been established as an indicator of the overall body strength of an individual ${ }^{[17]}$. Strong correlations between handgrip strength and various anthropometric traits, (weight, height, hand length etc.) have also been reported earlier ${ }^{[31-40]}$. The rationale of conducting the present study was to search for the correlations of handgrip strength with selected hand and arm anthropometric variables to excel the performance of the players as well as to avoid sport- specific injuries, which was the practical perspective of the study too. The hypothesis of the present study was that Indian female volleyball players would have greater handgrip strength than the controls and grip strength would carry significant correlations with the selected hand and arm anthropometric variables in them.

\section{METHODS AND SUBJECTS}

\section{Participants:}

The present cross-sectional study is based on 101 randomly selected Indian inter-university female volleyball players aged 18-25 years (mean age $20.52 \pm$ 1.40 years). An adequate number of controls ( $\mathrm{n}=100$, mean age $21.10 \pm 1.70$ ) with no particular athletic background were also collected from the same place for comparisons. The age of the subjects was recorded from the date of birth registered in their respective institutions. The subjects were divided in such a way that age 18 refers to the individuals aged 17 years and 6 months through 18 years and 5 months and 29 days. Exclusion criteria were set upon the knowledge of some genetic, psychological, neurological or chronic diseases affecting hand function and anthropometric characteristics ${ }^{[41,42]}$. A written consent was obtained from the subjects. The data were collected under natural environmental conditions in the morning (between 8 AM. To 12 noon).

\section{Anthropometric Measurements:}

Three anthropometric variables, i.e. height (HT), weight (WT) and body mass index (BMI), two hand anthropometric variables, i.e. right and left hand width and length, four arm anthropometric variables, i.e. upper arm length, lower arm length, upper extremity length, upper arm circumference and dominant right and non-dominant left hand grip strength were measured following standard techniques ${ }^{[43]}$ and were measured in triplicate with the median value used as the criterion.

The height was recorded during inspiration using a stadiometer (Holtain Ltd., Crymych, Dyfed, UK) to the 
nearest $0.1 \mathrm{~cm}$, and weight was measured by digital standing scales (Model DS-410, Seiko, Tokyo, Japan) to the nearest $0.1 \mathrm{~kg}$. BMI was then calculated using the formula weight $(\mathrm{kg}) /$ height $^{2}(\mathrm{~m})^{2}$. Hand length and hand width of both sides were measured by Vernier slide caliper (Starrett, 123 Series, U.S.A.). Upper arm length, forearm length, upper extremity length was measured by the first segment of the anthropometer rod and upper arm circumference was measured by steel tape and these measurements were taken on the subject's right side.

\section{Handgrip strength measurement:}

The grip strength of both right and left hands was measured using a standard adjustable digital handgrip dynamometer (Takei Scientific Instruments Co., LTD, Japan) at standing position with the shoulder adducted and neutrally rotated and elbow in full extension. The dynamometer was held freely without support, not touching the subject's trunk. The position of the hand remained constant without downward direction. The subjects were asked to put maximum force on the dynamometer thrice from both sides of the hands. The maximum value was recorded in kilograms. Anthropometric equipment and handgrip dynamometer were calibrated before each assessment. All subjects were tested after 3 minutes of independent warm-up. A thirty seconds time interval was maintained between each handgrip strength testing.

\section{Statistical analysis:}

Standard descriptive statistics (mean \pm standard deviation) were determined for directly measured and derived variables. The data showed normal distribution encouraging us to use parametric statistics. Independent t-test was used for comparisons between volleyball players and controls for all the measured variables. Pearson's correlation coefficients were used to establish the correlations of dominant and nondominant handgrip strength with other variables in volleyball players. Data were analyzed using SPSS (Statistical Package for Social Science) version 17.0. A $5 \%$ level of probability was used to indicate statistical significance.

\section{RESULTS}

Descriptive statistics of anthropometric characteristics and handgrip strength of Indian inter-university female volleyball players are shown in Table 1. Indian female volleyball players have higher mean values in almost all the variables studied, except right upper extremity

Table 1: Descriptive statistics of hand grip strength and some selected anthropometric characteristics in Indian inter-university female volleyball players

\begin{tabular}{|c|c|c|c|}
\hline Variables & $\begin{array}{c}\text { Volleyball } \\
\text { players }(n=101) \\
\text { Mean (SD) }\end{array}$ & $\begin{array}{c}\text { Controls } \\
(n=100) \\
\text { Mean (SD) }\end{array}$ & $P$-value \\
\hline Height (cm) & $164.78(4.00)$ & $159.41(4.82)$ & 0.03 \\
\hline Body weight (kg) & $58.16(5.54)$ & $53.00(7.69)$ & $<0.001$ \\
\hline Body mass index $\left(\mathrm{kg} / \mathrm{m}^{2}\right)$ & $21.39(1.58)$ & $20.90(3.17)$ & 0.2 \\
\hline Right hand width (cm) & $7.25(0.37)$ & $7.20(0.34)$ & 0.3 \\
\hline Left hand width (cm) & $7.19(0.34)$ & $7.09(0.33)$ & 0.04 \\
\hline Right hand length (cm) & $18.13(0.80)$ & $17.03(0.68)$ & $<0.001$ \\
\hline Left hand length $(\mathrm{cm})$ & $18.08(0.80)$ & $17.03(0.67)$ & $<0.001$ \\
\hline Right upper arm length (cm) & $33.38(1.88)$ & $31.24(1.68)$ & $<0.001$ \\
\hline Right forearm length $(\mathrm{cm})$ & $26.89(1.53)$ & $25.73(1.49)$ & $<0.001$ \\
\hline Right upper extremity length (cm) & $77.32(3.54)$ & $79.97(7.27)$ & 0.7 \\
\hline Right upper arm circumference $(\mathrm{cm})$ & $25.20(1.76)$ & $25.43(2.72)$ & 0.5 \\
\hline Dominant right hand grip strength (kg) & $27.04(2.64)$ & $22.69(3.82)$ & $<0.001$ \\
\hline Non-dominant left hand grip strength (kg) & $24.10(2.66)$ & $20.93(3.86)$ & $<0.001$ \\
\hline
\end{tabular}

SD: Standard Deviation 
Table 2: Inter-correlation matrix of hand grip strength and some selected anthropometric variables among Indian interuniversity female volleyball players

\begin{tabular}{|c|c|c|c|c|c|c|c|c|c|c|c|c|}
\hline Variables & WT & BMI & RHW & LHW & RHL & LHL & RUAL & RFAL & RUEL & RUAC & DHGS & NDLHGS \\
\hline HT & $0.66^{*}$ & $0.20^{\ddagger}$ & $0.69 *$ & $0.60 *$ & $0.57 *$ & $0.56^{*}$ & $0.78 *$ & $0.66^{*}$ & $0.77^{*}$ & $0.29 *$ & $0.49^{*}$ & $0.38^{*}$ \\
\hline WT & 1 & $0.87 *$ & $0.44^{*}$ & $0.45^{*}$ & $0.63 *$ & $0.58^{*}$ & $0.51^{*}$ & $0.52 *$ & $0.67 *$ & $0.56^{*}$ & $0.57^{*}$ & $0.35^{*}$ \\
\hline BMI & & 1 & 0.12 & 0.19 & $0.44 *$ & $0.39 *$ & 0.15 & $0.25 *$ & $0.37 *$ & $0.54 *$ & $0.43 *$ & $0.21^{*}$ \\
\hline RHW & & & 1 & $0.83 *$ & $0.41 *$ & $0.42 *$ & $0.60 *$ & $0.60 *$ & $0.56^{*}$ & 0.17 & $0.28 *$ & $0.26^{*}$ \\
\hline LHW & & & & 1 & $0.46^{*}$ & $0.53^{*}$ & $0.55^{*}$ & $0.59 *$ & $0.53^{*}$ & $0.25^{*}$ & $0.36^{*}$ & $0.29^{*}$ \\
\hline RHL & & & & & 1 & $0.98 *$ & $0.43 *$ & $0.52 *$ & $0.67 *$ & $0.20^{*}$ & $0.48 *$ & $0.35^{*}$ \\
\hline LHL & & & & & & 1 & $0.44^{*}$ & $0.54 *$ & $0.66^{*}$ & 0.16 & $0.48^{*}$ & $0.35^{*}$ \\
\hline RUAL & & & & & & & 1 & $0.63^{*}$ & $0.78 *$ & $0.35^{*}$ & $0.37 *$ & $0.28 *$ \\
\hline RFAL & & & & & & & & 1 & $0.76^{*}$ & 0.17 & $0.51 *$ & $0.41 *$ \\
\hline RUEL & & & & & & & & & 1 & $0.27^{*}$ & $0.52 *$ & $0.40^{*}$ \\
\hline RUAC & & & & & & & & & & 1 & 0.24 & 0.10 \\
\hline DHGS & & & & & & & & & & & 1 & $0.76^{*}$ \\
\hline
\end{tabular}

* Significant at 0.05 level; * Significant at 0.01 level; HT = Height; WT=Body weight; BMI= Body mass index; RHW= Right hand width; LHW= Left hand width; RHL=Right hand length; $L H L=$ Left hand length; $R U A L=$ Right upper arm length; $R F A L=$ Right forearm length; $R U E L=$ Right upper extremity length; RUAC $=$ Right upper arm circumference; DHGS= Dominant right hand grip; NDLHGS= Non-dominant left hand grip

length and right upper arm circumference than their control counterparts, showing statistically highly significant differences $(P<0.001)$ in all the variables except BMI, right hand width, right upper arm extremity and right upper arm circumference.

Bivariate correlations of the anthropometric characteristics and handgrip strength were examined in Indian inter-university volleyball players in Table 2 . Dominant hand grip strength had significantly positive correlations $(P \leq 0.01)$ with all the variables. Height and weight too, had significantly positive correlations $(P \leq 0.01)$ with all the variables. For the rest of the anthropometric variables, it was observed that almost all the hand and arm anthropometric variables were correlated significantly $(P \leq 0.05-0.01)$ with positive correlations to each other.

Table 3 shows the inter-correlation matrix of handgrip strength and some selected anthropometric variables in controls. Among the anthropometric variables and handgrip strength, few significantly

Table 3: Inter-correlation matrix of hand grip strength and some selected anthropometric variables in controls

\begin{tabular}{|c|c|c|c|c|c|c|c|c|c|c|c|c|}
\hline Variables & WT & BMI & RHW & LHW & RHL & LHL & RUAL & RFAL & RUEL & RUAC & DHGS & NDLHGS \\
\hline HT & 0.15 & $-0.27^{*}$ & $0.37 *$ & $0.45^{*}$ & $0.52 *$ & $0.47 *$ & $0.65^{*}$ & $0.35^{*}$ & 0.14 & -0.05 & 0.16 & 0.01 \\
\hline WT & 1 & $0.91 *$ & $0.21^{*}$ & 0.18 & 0.07 & 0.01 & 0.19 & 0.12 & 0.18 & $0.85^{*}$ & $0.22 *$ & 0.15 \\
\hline BMI & & 1 & 0.05 & -0.02 & -0.16 & $-0.20^{*}$ & -0.09 & -0.04 & 0.10 & $0.84 *$ & 0.15 & 0.14 \\
\hline RHW & & & 1 & $0.81 *$ & $0.41 *$ & $0.49 *$ & $0.39 *$ & $0.25^{\ddagger}$ & 0.05 & 0.10 & $0.43 *$ & $0.38 *$ \\
\hline LHW & & & & 1 & $0.39 *$ & $0.47 *$ & $0.45^{*}$ & $0.23^{\ddagger}$ & 0.08 & 0.10 & $0.31 *$ & $0.21^{*}$ \\
\hline RHL & & & & & 1 & $0.94 *$ & $0.45^{*}$ & 0.39 & 0.03 & 0.00 & 0.18 & 0.04 \\
\hline LHL & & & & & & 1 & $0.43^{*}$ & $0.31 *$ & 0.09 & -0.04 & $0.22^{\ddagger}$ & 0.10 \\
\hline RUAL & & & & & & & 1 & $0.25^{\ddagger}$ & 0.02 & 0.11 & 0.16 & 0.00 \\
\hline RFAL & & & & & & & & 1 & 0.04 & 0.02 & 0.19 & 0.04 \\
\hline RUEL & & & & & & & & & 1 & $0.21^{\ddagger}$ & 0.15 & 0.21 \\
\hline RUAC & & & & & & & & & & 1 & 0.11 & 0.08 \\
\hline DHGS & & & & & & & & & & & 1 & $0.81 *$ \\
\hline
\end{tabular}

${ }^{*}$ Significant at 0.05 level; * Significant at 0.01 level; HT = Height; WT=Body weight; BMI= Body mass index; RHW= Right hand width; LHW= Left hand width; RHL=Right hand length; $L H L=$ Left hand length; $R U A L=$ Right upper arm length; $R F A L=$ Right forearm length; RUEL $=$ Right upper extremity length; RUAC $=$ Right upper arm circumference; DHGS= Dominant right hand grip; NDLHGS= Non-dominant left hand grip 
positive correlations were noted. All the measurements were taken by JS and the inter-tester variability was also tested.

\section{DISCUSSION}

Anthropometric dimensions and morphological characteristics play an important role in determining the success of an athlete ${ }^{[44-46]}$. Quite naturally, the interest in anthropometric characteristics and body composition of athletes from different competitive sports has increased tremendously over the last decades. All ball games require comprehensive abilities including physical, technical, mental and tactical ones. Among them, physical abilities of the players are more important as these have marked effects on the skill of players and the tactics of the teams because ball games require repeated maximum exertion such as dashing and jumping ${ }^{[47]}$.

In volleyball, teams compete by manicures handling the ball above the head, height is considered to be the most important physical attribute. In the present study, the Indian female volleyball players have higher mean values in all the variables, except right upper extremity length and right upper arm circumference than their control counterparts. These differences were, might be, due to the effect of regular physical exercise and training of the players. When comparisons were made between Indian female volleyball players and their foreign counterparts, Indian female players had lesser mean values for height and weight $(164.78 \mathrm{~cm}, \pm 4.00$ and $58.16 \mathrm{~kg} \pm 4.54$ respectively) than the American $(176.70 \mathrm{~cm}, \pm 4.60$ and $69.70 \mathrm{~kg} \pm 10.80$ respectively) ${ }^{[48]}$ and Turkish $(174.00 \mathrm{~cm}, \pm 7.60$ and $61.1 \mathrm{~kg} \pm 8.70$ respectively) ${ }^{[49]}$ female volleyball players. These differences were, might be, due to the level of competitions the players participated. In the study, significantly greater height to body weight ratio $(\mathrm{H} / \mathrm{W}$ $=2.83$ ) among the Indian inter-university female volleyball players might be disadvantageous for them in attaining a good jumping height as they have to lift a greater weight.
In case of relationships of handgrip strength, a physical performance indicator, with height, weight, BMI and two hand- and four arm anthropometric characteristics, strong correlations were found. It was earlier reported too that handgrip strength had strong correlations with various anthropometric characteristics [14,15,49-52] and males attained stronger handgrip than their female counterparts ${ }^{[46]}$. Right and left hand grip strength was positively correlated with weight, height and body surface area ${ }^{[53]}$. The findings of the present study followed the same line showing strong positive correlations with dominant right and non-dominant left handgrip strength and all the hand-arm anthropometric variables studied.

The limitations of the study were that, firstly, male data could have also been incorporated to draw a generalized statement, and, secondly, national level players could have been taken into account to validate these correlations. The future scope of the study is immense. To search the talents in sport, to organize the gender-specific training program, to avoid sportsspecific injuries and finally to improve the performance of the players the findings of the present study carried immense practical implications.

\section{CONCLUSION}

It may be concluded that dominant handgrip strength had some strong positive correlations with all the variables studied in Indian inter-university female volleyball players. The data presented in the present study carry immense practical application and may be useful in future investigation on player selection, talent identification in volleyball and training program development.

\section{ACKNOWLEDGMENTS}

Authors are thankful to the coaches of the six Indian universities as well as to the participants for their kind 
cooperation. The authors are also thankful to the local ethics committee of the University for the approval of the study.

\section{Conflict of interests: None}

\section{REFERENCES}

1. Kunstlinger U, Ludwig HG, Stegemann J. Metabolic changes during volleyball matches. Int J Sports Med 1987;8:315-22.

2. Viitasalo J, Rusko H, Pajala O, et al. Endurance requirements in volleyball. Can J Appl Sport Sci 1987;12:194-201.

3. Polglaze T, Dawson B. The physiological requirements of the positions in state league volleyball. Sports Coach. 1992;15:32-7.

4. Fleck S, Case S, Puhl J, et al. Physical and physiological characteristics of elite women volleyball players. Canad J Appl Sport Sci $1985 ; 10: 122-6$.

5. Fry AC, Kraemer WJ, Weseman CA, et al. The effects of an off-season strength and conditioning program on starters and non-starters in women's intercollegiate volleyball. J Appl Sport Sci Res 1991;5:174-81.

6. Richards L, Olson B, Palmiter-Thomas P. How forearm position affects grip strength. Am J Occup Therap. 1996;50:133-9.

7. Bohannon RW. Reference values for extremity muscle strength obtained by handheld dynamometer from adults aged 20 to 79 years. Arch Phys Med Rehab 1997;78:26-32.

8. Bassey EJ, Harries UJ. Normal values for hand grip strength in 920 men and women aged over 65 years and longitudinal changes over 4 years in 620 survivors. Clin Sci 1993;84:331-7.

9. Budoff JE. The Prevalence of Rotator Cuff Weakness in Patients with Injured Hands. J Hand Surg 2004;29:1154-9.

10. Fry AC, Ciroslan MD, Fry CD, et al. Anthropometric and Performance Variables Discriminating Elite American Junior Men Weightlifters. J Strength and Cond Res 2006;20:861-6.

11. Smith T, Smith S, Martin M, et al. Grip Strength in Relation to Overall Strength and Functional Capacity in Very Old and Oldest Old Females. The Haworth Press Inc 2006; Pp:63-78.

12. Yasuo G, Daisaku T, Nariyuki M, et al. Relationship between Grip Strength and Surgical Results in Rotator Cuff Tears. Shoulder Joint 2005;29:559-62.

13. Poliquin C. The Poliquin International Certification Program Theory II Manual. East Greenwich, RI. 2006 ; Pp: 2-42.

14. Koley S, Singh J, Sandhu JJ. Anthropometric and physiological characteristics on Indian inter-university volleyball players. $J$ Hum Sport \& Exer 2010;5:389-99.

15. Koley S, Singh J, Kaur S. A study of arm-anthropometric profile in inter-university basketball players. Surb J Sports Sci 2010;5:3540.

16. Massey-Westrop N, Rankin W, Ahern M, et al. Measuring grip strength in normal adult: reference ranges and a comparison of electronic and hydraulic instruments. J Hand Surg 2004;29A:514-9.

17. Foo LH. Influence of body composition, muscle strength, diet and physical activity on total body and forearm bone mass in Chinese adolescent girls. Br J Nutr 2007;98:1281-7.

18. Nwuga V. Grip strength and grip endurance in physical therapy students. Arch Phys Med Rehab. 1975;56:296-9.

19. Kenjle K, Limaye S, Ghurge PS, et al. Grip Strength for Assessment of Nutritional Status of Children Aged 6-10 Years. J Nutr Sci Vitaminol 2005;51:87-92.

20. Brozek J. The assessment of motor function in adults. In: Malnutrition and Behaviour: Assessment of key issues. Nestle Foundation Publication series Vol 4, (Lausanne: Nestle Foundation). 1984; Pp: 268-79.

21. Watters DA, Haffejee AA, Angom IB, et al. Nutritional assessment by hand grip dynamometry. S Afr Med J 1985;68:585-7.

22. Vaz M, Thangam S, Prabhu A, et al. Maximal voluntary contraction as a functional indicator of adult chronic undernutrition. Br $J$ Nutr. 1996;76:9-15.

23. Jeejeebhoy KN. Nutritional assessment. Gastroentrol. Clin North Am 1998;27:347-69.

24. Manandhar MC. Undernutrition and impaired functional ability amongst elderly slum dwellers in Mumbai, India. Ph.D. Thesis, London School of Hygiene and Tropical Medicine. 1999.

25. Guo CB, Zhang W, Ma DG, et al. Hand Grip Strength: an Indicator of Nutritional State and the Mix of Postoperative Complications in Patients with Oral and Maxillofacial Cancers. Br J Oral Maxillofac Surg 1996;34:325-7.

26. Chilima DM, Ismail SJ. Nutrition and hand grip strength of older adults in rural Malawi. Public Health Nutr 2001;9:11-7. 
27. Pieterse S, Manandhar M, Ismail S. The association between nutritional status and hand grip strength in older Rwandan refugees. Eur J Clin Nutr 2002;56:933-9.

28. Kaur N, Koley S. An association of nutritional status and hand grip strength in female laborers and sedentary women of Jalandhar, Punjab, India. Anthropologist 2010;12:237-43.

29. Samson MM, Meeuwsen IB, Crowe A, et al. Relationships between physical performance measures, age, height and body weight in healthy adults. Age Ageing 2000;29:235-42.

30. Onder G, Penninx BW, Lapuerta P, et al. Change in physical performance over time in older women: the women's Health and Aging Study. J Geronol A Biol Sci Med Sci 2002;57:M289-93.

31. Malina RM, Zavaleta AN, Little BB. Body size, fatness, and leanness of Mexican American children in Brownsville, Texas: changes between 1972 and 1983. Am J Public Health. 1987;77:573-7.

32. Ross CH, Rösblad B. Norms for grip strength in children aged 4-16 years. Acta Paediatrica 2002;91:617-25.

33. Singh AP, Koley S, Sandhu JS. Association of hand grip strength with some anthropometric traits in collegiate population of Amritsar. Orient Anthropol 2009;9:99-110.

34. Koley S, Singh AP. An association of dominant hand grip strength with some anthropometric variables in Indian collegiate population. Anthropol. Anz 2009;67:21-8.

35. Koley S, Kaur N, Sandhu JS. Association of hand grip strength and some anthropometric traits in female labourers of Jalandhar, Punjab, India. J Life Sci 2009;1:57-62.

36. Jurimae T, Hurbo J, Jurimae J. Relationship of handgrip strength with anthropometric and body composition variables in prepubertal children. J Copmar Hum Biol 2009;60:225-38.

37. Kaur M. Age-related changes in hand grip strength among rural and urban Haryanvi Jat females. J Copmar Hum Biol 2009; 60:44150 .

38. Henneberg M, Harrison GA, Brush G. The small child: anthropometric and physical performance characteristics of short-for-age children growing in good and in poor socio-economic conditions. Euro J Clin Nutr 1998;52:286-91.

39. Henneberg M, Brush G, Harrison GA. Growth of specific muscle strength between 6 and 18 years in contrasting socioeconomic conditions. Am J Phy Anthrop 2001;115:62-70.

40. Koley S, Kaur N. A Study on Handgrip Strength and some Anthropometric Variables in Younger and Older Female Laborers of Jalandhar, Punjab, India. Int J Biol Anthropol. 2009; 3(2).

41. Malina RM, Bushang PH. Anthropometric asymmetry in normal and mentally retarded males. Ann Hum Biol 1984;11:515-31.

42. Brill T, Stier S. Hand parameter differences between psychiatric patients and normal controls: a preliminary evaluation. Isr $J$ Psychiatry Relat Sci 1999;36:105-14.

43. Lohmann TG, Roche AF, Martorell R. Anthropometric Standardization Reference Manual. Champaign, IL: Human Kinetics Books.1988.

44. Rico-Sanz J. Body composition and nutritional assessments in soccer. Int J Sport Nutr 1998;8:113-23.

45. Wilmore JH, Costill DL. Physiology of Sports and Exercise. 2nd ed. Champaign, Human Kinetics.1999.

46. Keogh J. The use of physical fitness scores and anthropometric data to predict selection in an elite under-18 Australian rules football team. J Sport Sci Med 1999;2:125-33.

47. Tsunawake N, Tahara Y, Moji K, et al. Body Composition and physical fitness of female volleyball and basketball players of the Japan inter-high school championship teams. J Physiol Anthropol. Appl Hum Sci 2003;22:195-201.

48. Ferris DP, Signorile F, Caruso JF. The relationship between physical and physiological variables and volleyball spiking velocity. $J$ Strength and Cond Res 1995;9:32-6.

49. Belgin B, Tuncay C, Aydin O, et al. Volumetric determination of medial epicondyle and lateral epicondyle of humerus in male and female volleyball players. Okajimas Folio Anat Jpn 2003;8:63-70.

50. Benefice E, Malina R. Body size, body composition and motor performances of mild-to-moderately undernourished Senegalese children. An Hum Biol. 1996; 23: 307-21.

51. Koley S, Yadav MK. An association of hand grip strength with some anthropometric variables in Indian cricket players. FACTA UNIVERSITATIS, Series: Physical Education and Sports 2009;7:113-23.

52. Koley S. Kaur N, Sandhu JS. Association of hand grip strength and some anthropometric traits in female labourers of Jalandhar, Punjab, India. J Life Sci 2009;1:57-62.

53. Chatterjee S, Chowdhuri BJ. Comparison of grip strength and isometric endurance between the right and left hands of men and their relationship with age and other physical parameters. J Hum Ergol 1991;20:41-50. 